\title{
Skewness Preference and IPO Anomalies in China
}

\author{
Wei Tang \\ School of Economics, Fudan University, China \\ E-mail: 14110680034@fudan.edu.cn \\ Tianhao Wu \\ Department of Statistics, Yale University, USA \\ E-mail: tianhao.wu@yale.edu \\ and \\ Liheng $\mathrm{Xu}$ \\ School of Economics, Fudan University, China \\ E-mail: 12210680129@fudan.edu.cn
}

Due to investors' unique structure and new transaction share rules, speculation in China's IPO market is common. In this paper, we investigate many anomalies in IPOs that produce huge initial return, long-term return reversal and high turnover rate from the perspective of investors' desire to gamble (skewness preferences). Based on Cumulative Prospect Theory, this paper theoretically and empirically verified that there is a significant impact on first day and long-term returns. Using all issued IPO between 2009 and 2012 as a study sample, the empirical results show that the increase of a standard deviation of skewness preference, and the first day returns increase $5.478 \%$. Moreover, when the market environment is favorable, the positive sentiment of investors will make the effect of skewness preferences stronger. In the long run, the stronger the expected skewness is, the more negative the long-term risk premium is, and the lower the possibility of new shares that institutional investors continue to hold. In addition, skewness preferences across different industries, different financing scale, and different issue price has a significant difference.

Key Words: Skewness Preference; Expected Skewness; Idiosyncratic Skewness; Anomalies of IPO.

JEL Classification Numbers: G11, G12, G14. 


\section{INTRODUCTION}

Recent decades have witnessed a heated discussion on IPO anomalies in finance studies. New shares often exhibit high first-day returns (Ritter, 1984; Tinic, 1988; Huang, 1999) with high turnover rate (Shao, 2011), while long-run performance is poor (Ritter, 1991; Loughran \& Ritter, 1995; Keischnick, 2003). The three biggest anomalies of IPOs termed by researchers are prevalent all around the world, but are especially distinct in China's IPO stock market.

China's IPO stock market shows abnormal high first day returns and high turnover rate. The average first day return from 1990 to 2013 reached $118.4 \%$ in China's IPO stock market, which was far above the average return of IPO market in developed countries. and also surpasses the level of other developing countries. New shares issuance exhibit "three highs": high issue price, high $\mathrm{P} / \mathrm{E}$ ratio and high level of financing size. High first day returns are also accompanied by high turnover rate in China's IPO market. The average first day turnover rate from 1995 to 2013 reached $64.7 \%$, where maximum level is as high as $95.9 \%$. As China's stock market adopted " $T+1$ " trading rules ${ }^{1}$, an average turnover rate of $64.7 \%$ indicated that more than half of the new shares are sold out by the initial holders on the first day.

What drives these anomalies? This question has been central to finance studies for a long time. Two streams of research have developed around this question. One is based on the efficient market hypothesis, holding the opinion that high initial return of IPOs is a result of underpricing in primary market, while secondary market is efficient. The other opinion rests on behavioral finance, asserting that the primary market is efficient and high first day return of IPOs is due to the fact that IPOs are overvalued in secondary market. The former traditional explanations focus on information asymmetry, e.g., "winner's curse" derived from information asymmetry between investors (Rock,1986), "information disclosure" model from information asymmetry between underwriters and investors (Benveniste \& Spindt, 1989), "principle and agent" model from information asymmetry between underwriters and issuers (Loughran \& Ritter, 2003), and "signaling" model from information asymmetry between issuers and investors (Ibbotson, 1975). However, Ritter (2002) argues that information asymmetry alone cannot explain $18 \%$ initial return of IPO in the U.S. Because of the unique trading rules and investors composition in China's IPO market, the explanative power of this theory is not strong enough in China's IPO setting, either (Han et al. 2007). Therefore, recently, researchers started to turn to behavioral finance perspectives to look for better explanations, realizing that investors' irrational behavior can affect asset price, and this

${ }^{1}$ Stocks bought today can only be sold in the next transaction date. 
behavior produces an effect that is not random. For example, multiple works consider the effects of investor overoptimism in asset pricing (Derrien 2005).

Recent work has introduced another type of investor irrationality into asset pricing: the propensity to gamble. For instance, Markowitz (1952) once argued that some investors may prefer to "take large chances of a small loss for a small chance of a large gain." Theory researchers also found that the expected utility theory of Von Neumann and Morgenstern (1944) doesn't reflect investors' risk attitudes in experimental evidence. For example, Barberis and Huang (2008) show that decisions by investors who prefer larger gains with smaller probability are likely to make stocks with idiosyncratic skewness be overpriced, according to Cumulative Prospect Theory. The endogenous probabilities model (Brunner- merier \& Paker, 2005) and heterogeneous agent model (Mitton \& Vorkink, 2007) also obtained similar conclusions: when investors over-value low-probability gains, stocks with positive skewness will be over- priced. Empirical studies provide evidence to support the prediction: Zhang (2006), Boyer et al. (2010) and Chang et al (2013) show that stocks with right skewness reveal a lower average return and negative risk premium. Green and Hwang (2008) also found that IPOs with high skewness experience higher first day return, and lower long term payoff, using U.S. data.

We focus on the China setting to examine the explanative power of investors' propensity to gamble on IPO anomalies for two reasons. Firstly, China's IPO market is mostly composed of individual investors. For most of the individual investors, it is usually their first attempt to participate in the IPO market ${ }^{2}$. It is possible that many investors join the market with little awareness of the risk. Compared with institutional investors, individual investors are more information disadvantaged (Chemmanur et al., 2010) and suffer from cognitive bias (Battalio et al., 2005). They are also more likely to be influenced by sentiment and propensity to gamble. For example, Kumar (2009) found that individual investors prefer lottery-like stocks, whose returns are right skewed, while institutional investors are relatively patient (Kumar, 2005). When the market is favorable, new shares are more likely to be traced by irrational investors (Cook et al., 2006; Coaley et al., 2008). Secondly, individual investors in China's stock market show more gambling attitude and prefer lottery-like stocks (Zheng, 2013). Lottery tickets offer a tiny probability of a huge gain and a large probability of small loss. Lottery-like stocks share qualitatively similar characteristics, captured by its right skewness of returns. Therefore, investors looking for "cheap bets" will be attracted by low-price stocks with higher skewness,

\footnotetext{
${ }^{2}$ According to statistics by Shenzhen Stock Exchange, among investors who buy stocks on days being listed, up to $71.49 \%$ are the first time trading and $15.50 \%$ are the second time trading. That's to say, $87 \%$ or so of investors only trade no more than twice.
} 
coinciding with the wide spread belief in China stock market: "new shares will never fail" or "new issued stocks, small size stocks or stocks with bad performance before, will outperform in the future". These are supported by the Kernel Density Curve of the new shares' return in China's IPO market. The curve shows clear right skewness. Figure 1 (a) shows the density curves of new shares and market index. We can see that return of new shares is right skewed compared to return of market index and the right tails are fatter. From Figure 1 (b) (c) (d), we can see that new shares initialized in Shenzhen Stock Exchange are more right skewed than those in Shanghai Stock Exchange ${ }^{3}$, stocks with smaller size are more right skewed than stocks with larger size, and stocks with lower IPO price are more right skewed than those with higher IPO price. All these coincide with investors' preference for new, small and low-price stocks in China's stock market.

In this study, we investigate the explanative power of investors' attitude of gamble towards three main IPO anomalies in China: high first day return, high turnover rate and long term under performance. In a stock market mostly composed by individual investors, we find that skewness preference is an important determinant of IPO anomalies. Our theoretical work assumes that individual investors make decisions with modifications of subjective probability and prefer lottery-like assets which is consistent with Cumulative Prospect Preference, while rational institutional investors follow traditional expected utility preference. The interaction between individual investors with gambling preference and institutional investors in IPO market shows the causal effect of skewness preference on IPO anomalies. Specifically, a higher skewness preference of individual investors results in a higher first day return, a higher turnover rate, and a lower long term performance. Our empirical results confirm the predictions. Using a sample of 897 A-share firms over 2009 to $2012^{4}$, we find the following results: (1) Expected skewness is positively associated with new share's first day return. A standard deviation increase in expected skewness results in 5.5\% first day return increase. (2) In the long run, high initial return stock will convert to its fundamental value. High expected skewness stocks reveal long term under performance. (3) New shares with high skewness exhibit high turnover rate, as a result of institutional investors selling the shares and individual investors obtaining. (4) Investor sentiment amplify the effect of skewness preference on stock return.

\footnotetext{
${ }^{3}$ In our sample, stocks in Shanghai Stock Exchange are all main-board while those in Shenzhen Stock Exchange are SME-board and second-board.

${ }^{4}$ We restricted the sample up to 2012 for the following reasons: 1, price limits are launched on the first day of being listed after 2012, thus trade practices changed. 2, we cannot use newly-listed IPO as sample because we focus on long-run return rates. 3, China Securities Regulatory Commission has been carrying out strict inspections for IPO companies after the end of 2012. And IPO was suspended between 11/16/2012 to $12 / 2013$.
} 
FIG. 1. kernel density curve of the new shares' return

(a)

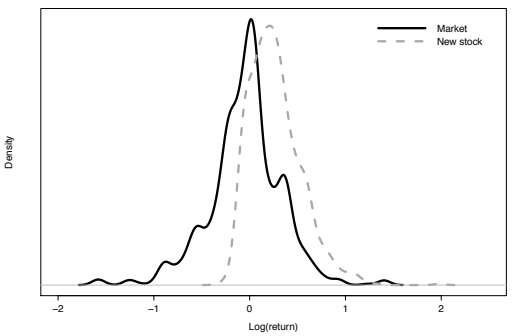

(c)

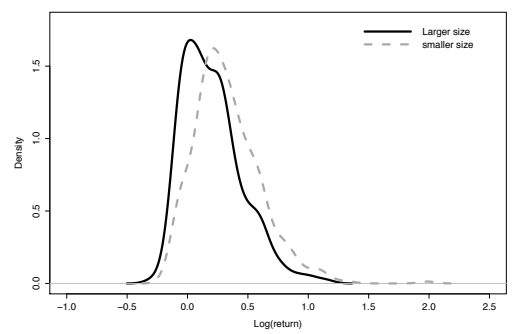

(b)

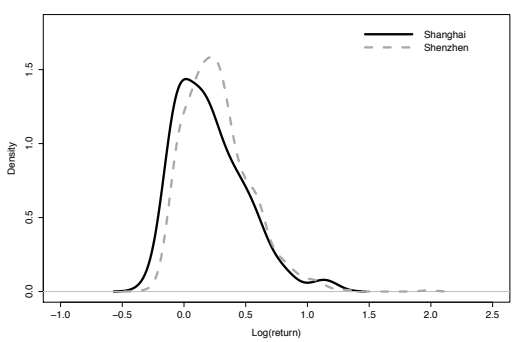

(d)

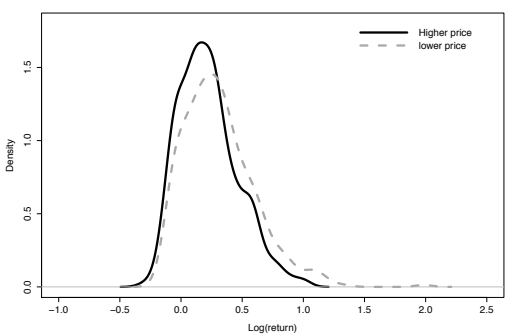

Note: market return rates in (a) are those of shanghai (securities) composite index on the first day of being listed. For clarification, we adjusted the coordinates. (b), (c) and (d) are grouped by boards, scale of financing and offering price accordingly and display the probability densities of returns. And the heights are bounded by P50 (the 50th percentile). Please note that the return rates here are logarithmic rates: if simple return rate is $R$, then the logarithmic rate is $\ln (1+R)$, which is continuous return rate.

Our paper contributes to prior literature in several aspects. Firstly, China's IPO stock market setting offers a unique opportunity to explore the explaining power of investors' gambling propensity to IPO anomalies. China's IPO secondary market is dominated by individual investors, who have been proved to establish severe gambling preference. Given the phenomenon that China's IPO market exhibits distinct anomalies, it is highly possible that investors' skewness preference plays an important role driving the anomaly. Moreover, first day trading of IPOs has no daily limit, providing a true reflection of investors' preference. Secondly, the theoretical model developed in this paper answers the question why skewness preference would result in the IPO anomalies. It assumes individual investors prefer lottery-like assets with modification of subjective probability, have gambling preference indicated by Cumulative Prospect Theory, while rational institutional investors follow traditional expected utility theory. The 
interaction between individual investors with gambling preference and institutional investors shows the causal effect of skewness preference on IPO anomalies, providing empirical evidence. Thirdly, this paper uses IPO first day opening price rather than offer price to calculate idiosyncratic skewness, which is more realistic and alleviate the concern that high skewness is merely a result of relatively low issuing price.

The paper proceeds in the following ways. Section 2 presents the hypothesis and develops a theoretical model. Section 3 explains the sample data and empirical strategy. Section 4 gives the empirical results. Last section concludes.

\section{THEORETICAL MODEL}

Assume a firm is going to hold its initial public offering with offering price $P_{0}$ and Quantity $Q$. The demand side has two types of investors: Rational investors (denoted by $R$ ) and Gambling investors (denoted by $G$ ). Rational investors make decisions based on fundamentals and are usually composed of institutional investors, while gambling investors prefer new shares with high payoff with low probability and are usually composed of individual investors.

The game proceeds in three stages. At $t=0$, underwriters obtain new shares with quantity $Q$ and price $P_{0}$ from issuers. They are sellers of new shares in the IPO stock market. The offer price is determined at the end of book building, prior to the start of selling. $t=1$ is the initial trading day when new shares are sold to rational investors and gambling investors. At $t=2$, some gambling investors might leave because of changing market situation. If gambling investors leave, only rational investors stay. Assume the probability for gambling investors to leave is $\gamma$ and the probability to stay is $1-\gamma . \nu$ denotes the true value of new shares, which represents the discounted future cash flows. Stock price after $t=2$ is $P_{T}$, where $P_{T}=\nu+\delta^{5}$.

The model considers three types of players: underwriters (sellers), rational investors (buyers) and gambling investors (buyers). Assume the support and the distribution of $\delta$ satisfies $\{-\varepsilon, 0, \varepsilon ; p, 1-2 p, p\}$. Here $1<p<1$ and $p \ll 1$. For simplicity, we assume that underwriters are all rational investors ${ }^{6}$. Thus, underwriters' expectation on the share price $P_{T}$ is $E\left(P_{T}\right)=\nu$.

Rational investors utility function has the form as followed:

$$
U_{R}=\omega+E\left(P_{T}\right) * x
$$

\footnotetext{
${ }^{5} P_{T}$ means the long-run prices of stocks are based on disturbance of real values.

${ }^{6}$ The conclusions are invariant without this assumption.
} 
Where $\omega$ represents wealth, $x$ denotes quantity of holding stocks. Thus we can acquire demand function of rational investors by taking derivatives of $U_{R}$ with respect to $x$ :

$$
P_{R}=\frac{\partial U_{R}}{\partial x}=\nu
$$

That is, rational investors buy the new shares according to its fundamental value. Gambling investors prefer stocks of high payoff with small probability. According to Cumulative Prospect Theory, we can adjust the support and the distribution of $\delta$ to the form: $\left\{-\varepsilon, 0, \varepsilon ; p_{2}, 1-p_{1}-p_{2}, p_{1}\right\}$. We assume $p_{1}>p$ and $p_{2}<p$ to reflect gambling investors' preference for lotterylike assets. Larger gambling preference indicates larger gap between $p_{1}$ and $p_{2}$. The utility function of gambling investors has the following form:

$$
\begin{gathered}
U_{G}=\omega+\sum_{\varepsilon} \pi(\delta) V\left(\nu_{\delta}, x\right) \\
V(\nu+\delta, x)=(\nu+\delta) * x-\frac{1}{2} \lambda x^{2}
\end{gathered}
$$

where $\omega$ represents wealth, $V(\nu+\delta, x)$ denotes the gambling investor's utility from holding $x$ stocks when the stocks are valued at $\nu+\delta$ and it shows diminishing marginal return as $x$ increases. Thus, the demand function of gambling investors becomes

$$
P_{G}=\nu+\left(p_{1}-p_{2}\right) * \delta-\lambda x
$$

Denote $a \equiv\left(p_{1}-p_{2}\right) \delta$, we have

$$
P_{G}=\nu+a-\lambda x
$$

a represents the overvaluation of stock value caused by gambling preference. A larger a represents a stronger preference for gambling, and a higher overvaluation of the stock. Underwriters choose a quantity to sold at $t=1$ and $t=2, q_{1}$ and $q_{2}$, to maximize its utility.

$$
\begin{aligned}
& \max _{q_{1}, q_{2}} q_{1} P_{1}+q_{2} E\left(P_{2}\right)-P_{0} Q \\
& \text { s.t. } q_{1}+q_{2}=Q, \quad q_{1} \geq 0, q_{2} \geq 0
\end{aligned}
$$

Here $P_{1}$ represents the stock price at $t=1, E\left(P_{2}\right)$ represents expectation price at $t=2$. For simplicity, we assume the exogenous parameter $\lambda$ satisfies $Q \leq \frac{\lambda}{a} \equiv \bar{Q}^{7}$.

\footnotetext{
${ }^{7}$ Other possibilities of the parameters will make the computations complex, but will not change our conclusions.
} 
Lemma 1. If $Q \leq \frac{\lambda}{a} \equiv \bar{Q}$, underwriters will sell all $q_{1}^{*}$ quantity of new shares to gambling investors at $t=1$, and $P_{1}^{*}=\nu+a-\lambda q_{1}^{*}$. At $t=2$, if gambling investors leave the market, $q_{2}^{*}$ quantity of new shares will be sold to rational investors. If gambling investors stay, $q_{2}^{*}$ new shares will be all sold to gambling investors, and $P_{2}^{*}=\nu+a-\lambda q_{2}^{*}$, i.e., $E\left(P_{2}^{*}\right)=$ $\gamma \nu+(1-\gamma)\left(\nu+a-\lambda q_{2}^{*}\right)$.

Proof. At $t=1$ and $t=2$, offering price of gambling investors is always higher than that of rational investors, i.e., $P_{G}=\nu+a-\lambda q_{t}^{*}>\nu+a-\lambda Q \geq \nu$. As a result, new shares will be always obtained by gambling investors if they are in the market.

Therefore, according to the first order condition,

$$
\nu+a-2 \lambda q_{1}^{*}-(1-\gamma)\left(\nu+a-2 \lambda q_{2}^{*}\right)=0
$$

We can have

$$
\left(q_{1}^{*}, q_{2}^{*}\right)=\left(\frac{(1-\gamma) Q+\frac{\gamma a}{2 \gamma}}{2-\gamma}, \frac{Q-\frac{\gamma a}{2 \gamma}}{2-\gamma}\right) \text { if } a<\frac{2 \lambda Q}{\gamma}
$$

And

I

$$
\left(q_{1}^{*}, q_{2}^{*}\right)=(Q, 0) \text { if } a \geq \frac{2 \lambda Q}{\gamma}
$$

LEMma 2. If $Q \leq \frac{\lambda}{a} \equiv \bar{Q}$, and $q_{1}^{*}, q_{2}^{*}>0$, we have

$$
P_{1}^{*}=E\left(P_{2}^{*}\right)
$$

Proof. If $q_{1}^{*}, q_{2}^{*}>0$ and $P_{!}^{*} \neq E\left(P_{2}^{*}\right)$, underwriters can sell stocks in a date with higher price, leading to $q_{1}^{*}=0$ or $Q_{2}^{*}>0$, contradiction.

Therefore, when $a<\frac{2 \lambda Q}{\gamma}$, we have

$$
P_{1}^{*}=E\left(P_{2}^{*}\right)=\nu+\frac{(4-3 \gamma) a+2 \lambda(1-\gamma) Q}{2(2-\gamma)}
$$

I

When $Q, \lambda, \gamma, \bar{\nu}$ are given, we have the following propositions.

Proposition 1. The first day return $\frac{P_{1}^{*}}{P_{0}}$ increases with a.

Proof. If $a<\frac{2 \lambda Q}{\gamma}, \frac{\partial P_{1}^{*}}{\partial a}=\frac{(4-3 \gamma)}{2(2-\gamma)}>0$ 
Proposition 2. New shares' long term expected payoff $E\left(P_{T}\right) / P_{1}^{*}$ decreases with gambling preference a.

Proof. Similar as Proposition 1.

Proposition 3. New shares' turnover rate $q_{1}^{*} / Q$ increases with gambling preference $a$.

Proof. If $a<\frac{2 \lambda Q}{\gamma}, \frac{\partial q_{1}^{*}}{\partial a}=\frac{\gamma}{2(2-\gamma) \lambda}>0$, and $\frac{\partial\left(q_{1}^{*}+(1-\gamma) q_{2}^{*}\right)}{\partial a}=\frac{\gamma^{2}}{2 \lambda}>0$.

\section{DATA AND EMPIRICAL STRATEGY}

\subsection{Data}

The dataset includes IPO firms in Shanghai and Shenzhen stock exchanges from 2009 to 2012 . The sample period starts from 2009 because China's stock market stopped issuing new shares in September 2008 to stabilize financial market and resumed in June 2009. Excluding two firms that have delisted during the sample period, 879 firms are included in the sample. From 2009 to 2012, transaction rules and new share issuing policies are relatively consistent, and the number of firms accumulated is enough to conduct the analysis. Data are obtained from Wind, which lists stock's historical price, trading volume, industry which it belongs to ${ }^{8}$, etc.

\subsection{Variable Construction}

3.2.1. Gambling Preference-Skewness

It is well documented that investors may prefer lottery-like assets, i.e., assets have small probability with large payoff. Empirically, this skewness preference is not easy to measure using transaction data. Zhang (2006) proposed a method to measure skewness preference using expected skewness. Specifically, it uses recent returns from industry peers to compute the new stock's expected skewness, reflecting investors' expectation on the new share.

$$
\text { Skew }_{i, t}=\frac{\left(P_{99}-P_{50}\right)-\left(P_{50}-P_{1}\right)}{\left(P_{99}-P_{1}\right)}
$$

$P_{j}$ is the $j$-th percentile of an empirical distribution generated from returns of industry peers before the corresponding new stock goes public.

\footnotetext{
${ }^{8} \mathrm{By}$ merger and acquisition (M\&A) or the change of main business, the industry which it belongs to may change. So we traced the information of industries that all stocks belong to.
} 
Intuitively, the expected skewness measure captures the right tail's distance to the median relative to left tails. If right tails are further away from the median, the numerator would be positive, leading to a positive skewness and a higher gambling preference. This expected skewness measure is well suited to China's stock market. In China, if a certain industry is "hot" at a given moment, new shares of that industry is more likely to be followed by investors. We use weekly returns of peer firms six weeks (4 weeks and 8 weeks as robustness check) before the new share's IPO to calculate expected preference.

Different from the above measure, another commonly used measure of skewness is third central moment (Boyer et al. 2010).

$$
\begin{aligned}
i \nu_{i, t} & =\left(\frac{1}{N(t)} \sum_{d \in s(t)} \varepsilon_{i, d}^{2}\right)^{1 / 2} \\
i s_{i, t} & =\frac{1}{N(t)} \frac{\sum_{d \in s(t)} \varepsilon_{i, d}^{3}}{i \nu_{i, t}^{3}}
\end{aligned}
$$

where $i \nu_{i, t}$ denotes the idiosyncratic volatility of stock $i$ at time $t$, and $i s_{i, t}$ represents the idiosyncratic skewness of stock $i$ at time $t . S(t)$ is the set of days after the stock goes public and $N(t)$ is the number of trading days in this set. Residual $\varepsilon_{i, d}$ is obtained from the following regression:

$$
R_{i, d}=\alpha_{i}+\beta_{i, d} R_{m, d}+\gamma_{i} R_{m, d}^{2}+\varepsilon_{i, d}
$$

This model is an extension of CAPM (Mitton \& Vorkink, 2007), where $R_{i, d}$ denotes the excess return of stock $i$ on day $d, R_{m, d}$ represents the excess return of market index on day $d$. A large $i s_{i, t}$ indicates higher skewness preference. We calculate skewness preference of each stock for trading days of 30,45 and 60 .

\subsubsection{Investor sentiment}

We use individual investors' bullishness-oversubscription as proxy for investor sentiment. Oversubscription is a common measure to capture investor sentiment (Derrien, 2005). In China's IPO market, a fraction of new shares are reserved for individual investors before they are available to retail investors on the first day of trading in the secondary market. Oversubscription, which is equal to the ratio of individual investors' actual demand to volume initially offered to individual investors, captures individ- 
ual investors' bullishness for the stock. A larger oversubscription indicates a higher bullishness of individual investors for the stock ${ }^{9}$.

\subsubsection{Dependent variable}

a. First day return

$S R_{i, t}$ represents first day return of new shares. It is calculated by substracting issuing price from first day closing price, scaled by issuing price, i.e.,

$$
S R_{i, t}=\frac{P_{1}-P_{0}}{P_{0}}
$$

where $P_{1}$ denotes first day closing price and $P_{0}$ represents issuing price.

b. Long term return (Ritter, 1991)

$L R_{i, t}$ represents adjusted long term return of stock $i$.

$$
L R_{i t}=\frac{P_{T}}{P_{1}}-\frac{P_{T}^{\text {market }}}{P_{1}^{\text {market }}}
$$

$P_{1}$ and $P_{1}^{\text {market }}$ denote the closing price of new stock and market index on the first day, respectively. $P_{T}$ and $P_{T}^{\text {market }}$ denote the closing price of the stock and market index on day $T$.

c. Turnover rate group

Turnover $_{i, t}$ denotes new share's turnover rate on the first day. We ranked the new stocks according to turnover rate and sort the sample into three groups: High turnover rate group, Medium turnover rate group and Low turnover rate group.

d. Institutional ownership change

We use $\Delta$ InsInvestor $_{i, t}$ to denote institutional ownership change ${ }^{10}$. We define $\Delta$ InsInvestor $_{i, t}=1$ if the number of institutions who hold the stock remain same or increase, and $\Delta$ InsInvestor $_{i, t}=0$ if number of institutions decrease $^{11}$.

\subsubsection{Control variables}

\footnotetext{
${ }^{9}$ We applied the reciprocal of oversubscription (that is, lot of new issues) as explanatory variable, chance of lot is announced by Exchange. Lower lot implies higher bullishness of individual investors.

${ }^{10}$ For the reason of limited data, we compare the first ten shareholders exposed before company listing and the most recent indication of the first ten shareholders after listing by shareholding ratio. And we identity individual investors and institutional investors by the types of shareholders.

${ }^{11}$ As robust check, we also consider the total amount of shares of institutional investors and create indicators for whether the numbers decrease or not.
} 
We use firm age (see Baron, 1982; Beatty and Ritter, 1986), market return, issuing price to earnings ratio, issuing size, issuing price, overall market valuation and underwriter reputation as control variables ${ }^{12}$.

A summary statistics of the variables is included in table B (see appendix).

\section{3. $\quad$ Regression models}

Firstly, we examine the impact of skewness preference on first day return.

$$
S R_{i, t}=\beta_{0}+\beta_{1} \text { Skewness }_{i, t}+\beta_{2} X_{i, t}+\varepsilon_{i, t}
$$

Secondly, we examine the impact of skewness preference on stock's long term performance.

$$
L R_{i, t}=\beta_{0}+\beta_{1} \text { Skewness }_{i, t}+\beta_{2} X_{i, t}+\varepsilon_{i, t}
$$

Thirdly, we use probit model to examine the impact of skewness preference on stock's turnover rate.

$P\left(\right.$ Turnover $_{i, t}=H, M \mid$ Skewness $\left._{i, t}, X_{i, t}\right)=\phi\left(\beta_{0}+\beta_{1}\right.$ Skewness $\left._{i, t}+\beta_{2} X_{i, t}\right)$ $P\left(\Delta\right.$ InsInvestor $_{i, t}=1 \mid$ Skewness $\left._{i, t}, X_{i, t}\right)=\phi\left(\beta_{0}+\beta_{1}\right.$ Skewness $\left._{i, t}+\beta_{2} X_{i, t}\right)$

Fourthly, we examine the impact of skewness preference after controlling investor sentiment.

$Y_{i, t}=\beta_{0}+\beta_{1}$ Skewness $_{i, t}+\beta_{2}$ Skewness $*$ Sentiment $+\beta_{3}$ Sentiment $+\beta_{4} X_{i, t}+\varepsilon_{i, t}$

Where $Y_{i, t}$ is $S R_{i, t}$ or $L R_{i, t}$.

\section{EMPIRICAL RESULTS}

\subsection{Descriptive Statistics}

We have two skewness preference measures: expected skewness and idiosyncratic skewness. Expected skewness captures the expected gambling preference of individual investors by utilizing industry peers' return distribution before the firm goes public. Idiosyncratic skewness captures the realized gambling preference of individual investors by calculating its own third central moment using returns realized after the firm goes public. The

\footnotetext{
${ }^{12}$ Market return is expressed as market return rate on ten days before IPO; market value is the level of $P / E$ ratio of the whole market; underwriter reputation is one for the levels above AA.
} 
two measures should both reflect individual investors' preference for lotterylike assets. We sort the sample into three groups according to expected skewness and idiosyncratic skewness, respectively, as in Table 1. Both for expected skewness and idiosyncratic skewness, high skewness group has higher first day return than low skewness group, and the difference in first return between high and low groups remains significantly positive across all skewness measures (expected skewness calculated from 4 weeks, 6 weeks and 8 weeks pre-IPO, and idiosyncratic skewness calculated from 30, 45 and 60 trading days).

TABLE 1.

Gaming Preference and Price Increase of New Issues On the First Day

\begin{tabular}{|l|c|c|c|}
\hline \multirow{2}{*}{ Expected skewness } & \multicolumn{3}{|c|}{ First day return(\%) } \\
\cline { 2 - 4 } & 4 weeks & 6 weeks & 8 weeks \\
\hline High & 47.59 & 45.05 & 44.90 \\
\hline Median & 35.02 & 38.13 & 34.62 \\
\hline Low & 25.50 & 24.93 & 28.55 \\
\hline \multirow{2}{*}{ High-Low } & $22.09^{* * *}$ & $20.13^{* * *}$ & $16.35^{* * *}$ \\
\cline { 2 - 4 } & $(6.53)$ & $(5.29)$ & $(4.71)$ \\
\hline Idiosyncratic skewness & \multicolumn{3}{|c|}{ First day return(\%) } \\
\cline { 2 - 4 } & 30 days & 45 days & 60 days \\
\hline High & 48.78 & 47.85 & 49.16 \\
\hline Median & 34.76 & 33.84 & 33.69 \\
\hline Low & 24.57 & 26.43 & 25.25 \\
\hline \multirow{2}{*}{ High-Low } & $24.21^{* * *}$ & $21.42^{* * *}$ & $23.91^{* * *}$ \\
\cline { 2 - 4 } & $(6.047)$ & $(5.318)$ & $(6.069)$ \\
\hline
\end{tabular}

Note: here we group IPOs to three parts by its expected skewness, and each group takes up $1 / 3$. Averages are taken within each group. t-values are between parentheses.

We also divided the sample into subgroups according to listing years. In each year, the subsample is further sorted on expected skewness or idiosyncratic skewness. Figure 2 presents average first day return of stocks in each year. Each year' average first day return exhibits an increasing pattern with skewness, except year of 2011 in which stocks of high expected skewness shows slightly less first day return than that of stocks with medium expected skewness. In addition, we can infer from Figure 2 that new share's first day return is highly associated with market environment, same as skewness.

\subsection{Features of IPO Skewness Preference, Characteristics of Financing Scale and Offering Price}


FIG. 2. gaming preferences of new issues and return on the first day in multiple years

(a)

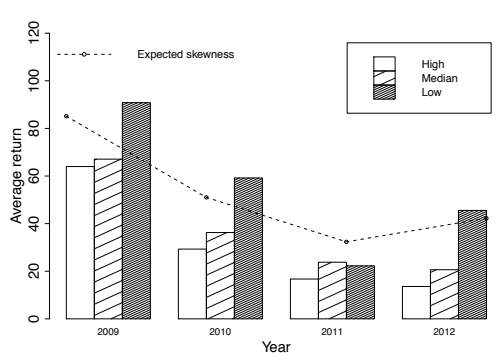

(b)

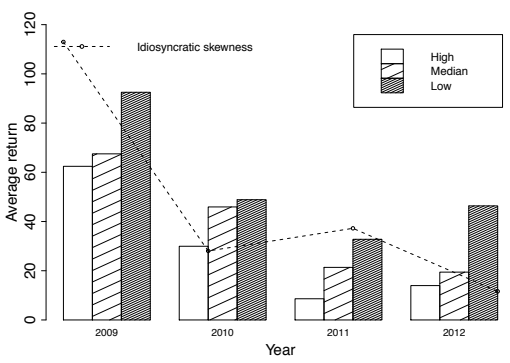

\subsubsection{IPO skewness preferences in different industries and trading boards}

Skewness preferences show great distinctions in different industries. Because of the different industries distributions in main board, middle and small enterprises board and second board, skewness preferences also vary in the three trading boards. Table A (see appendix) divide the sample into three subgroups according to expected skewness, and reports fraction of high, middle and low expected skewness stocks in each industry board.

Table A (see appendix) shows that in large and traditional industries such as textiles, financial services, and household appliances, most of the IPOs fall to low skewness portfolio $(53.57 \%, 45.45 \%$ and $41.67 \%$, respectively). Industries of chemicals, commerce and trade, mechanical equipment have more than $70 \%$ IPOs falling into medium and low skewness portfolios. Emerging sectors such as information services, electronics and biomedicine have similar distribution across high, medium and low skewness portfolios, perhaps due to the sluggish market environment after 2009. Industries correlated with infrastructure construction such as construction and construction materials, nonferrous metals, public utilities and mining, have high fraction of IPOs falling into high skewness portfolios $(47.92 \%$, $60 \%, 75 \%$ and $66.67 \%$ respectively). This phenomenon might be associated with macroeconomic policies during the sample period ${ }^{13}$.

Because of the different functions of main board, small and medium enterprises board and second board, average skewness preferences also vary

\footnotetext{
${ }^{13}$ Chinese government adopted economics stimulation plans after financial crisis in 2008 and affected economics development significantly in the following years, which was called "Four Trillion" plan. And the investments concentrated on infrastructure construction.
} 
in these trading boards. Table 2 reports the average expected skewness and first day return of the three boards. Small and medium enterprises board and second board shows slightly higher skewness preferences and higher average first day return than main board. This might be a result of industries with low skewness preferences clustered in main board, and industries with similar distributions across skewness clustered in small and medium enterprises board.

TABLE 2.

Distribution of Expected Skewness in Stock Boards

\begin{tabular}{|l|c|c|}
\hline & Expected skewness & First day return(\%) \\
\hline Stock Board & & \\
\hline Middle and small enterprises & 0.057 & 38.41 \\
\hline Start up & 0.053 & 34.41 \\
\hline Main & 0.032 & 29.51 \\
\hline Difference between & 0.025 & $8.90^{*}$ \\
Main and SME & $(1.506)$ & $(1.866)$ \\
\hline
\end{tabular}

Note: t-values are between parentheses.

\subsubsection{Skewness preferences with different issuing size and offer price}

Skewness preferences vary in stocks with different issuing size and offer price. In China's stock market, there is always excessive trading on small stocks. Usually, small stocks always trade at higher premium than large stocks, sometimes the premiums can reach as high as seven to eight multiples. A similar situation applies to new shares. In table 3, we divide the sample according to new share's issuing size into three groups: large size, medium size and small size, and then calculate each subgroup's first day average returns and skewness. It shows that the portfolio with small issuing size has much higher expected skewness and average first day return than portfolio with large size.

Table 3 also shows that new shares with lower offer price has higher skewness and average first day return than new shares with higher offer price, indicating that stocks with lower offer price is preferred than gambling investors.

\subsection{Regressions}

4.3.1. Effect of skewness on first day return

Table 4 reports the impact of skewness preference on a new stock's first day return. Column 1 shows the univariate result. First day return is positively associated with expected skewness. An increase of one standard 
TABLE 3.

Distribution of Expected Skewness by Scales and The Difference of Offering

\begin{tabular}{|l|c|c|}
\hline & Idiosyncratic skewness & First day return(\%) \\
\hline Scale of Financing & & \\
\hline Small & 0.240 & 50.94 \\
\hline Medium & 0.058 & 22.97 \\
\hline Large & 0.103 & 23.31 \\
\hline Difference between & $0.137^{*}$ & $27.63^{* * *}$ \\
Small and Large & $(1.736)$ & $(7.023)$ \\
\hline Offering Price & & 49.24 \\
\hline Low & 0.405 & 32.48 \\
\hline Middle & 0.092 & 26.65 \\
\hline Large & -0.044 & $22.59^{* * *}$ \\
\hline Difference between & $0.434^{* * *}$ & $(5.571)$ \\
Low and Large & $(4.978)$ & \\
\hline
\end{tabular}

Note: t-values are between parentheses.

deviation of expected skewness results in a $8.698 \%$ increase in first day return. Column 3 further added market and firm level control variables. The coefficient of expected skewness remains significant and positive. One standard deviation increase in expected skewness leads to $5.478 \%$ increase in first day return. In terms of control variables, issuing size and issuing price have negative impact on first day return, indicating that investors in China's market prefer small stocks, and stocks that are priced low. Market return affects positively on first day return, while $P / E$ ratio, firm age and underwriter reputation have no significant impact on first day return. Column 4 further controls firm's IPO year. Coefficient of expected skewness increased to 47.271 , compared to 41.817 in column 3. A standard deviation increase in expected skewness will result in a $6.193 \%$ increase in first day return. Considering the average first day return of IPO 36.04\%, a $6.193 \%$ increase is of significant magnitude ${ }^{14}$.

Column 2 and Column 5 use idiosyncratic skewness as an alternative measure of skewness preference. The coefficient of idiosyncratic skewness is still positive and significant. As the calculation of expected skewness uses the extreme return of a stock, it may also reflect investors' uncertainty toward the valuation of the stock, while the uncertainty will also contribute

\footnotetext{
${ }^{14}$ Green and Huang (2011) found that IPO rises by $1.5 \%$ when expected skewness increases by one unit of standard deviation, and the average increase of IPS is around $17.6 \%$, by using data from 1975 to 2008 of the U.S. Therefore, gamming preferences are much more influential on return rate during the first day in China.
} 
to increase in first day return. To rule out the possibility, we calculate the expected right skewness and left skewness. If the right and left skewness reflect the evaluation uncertainty, their effect on first day return should both be positive and symmetric. The empirical result (Column 6) shows that the effect of left skewness is negative, indicating that the effect of expected skewness on first day return is not due to valuation uncertainty.

TABLE 4

Impact of Gaming Preference on Return Rate on the First Day Issued

\begin{tabular}{|c|c|c|c|c|c|c|}
\hline & \multicolumn{6}{|c|}{ First day return(\%) } \\
\hline & $(1)$ & $(2)$ & $(3)$ & $(4)$ & $(5)$ & $(6)$ \\
\hline $\begin{array}{l}\text { Expected } \\
\text { skewness }\end{array}$ & $\begin{array}{c}66.395^{* * *} \\
(11.393) \\
\end{array}$ & & $\begin{array}{c}41.817^{* * *} \\
(10.230)\end{array}$ & $\begin{array}{c}47.271^{* * *} \\
(9.942) \\
\end{array}$ & & \\
\hline $\begin{array}{l}\text { Expected left } \\
\text { skewness }\end{array}$ & & & & & & $\begin{array}{c}-136.066^{* * *} \\
(41.636)\end{array}$ \\
\hline $\begin{array}{l}\text { Expected right } \\
\text { skewness }\end{array}$ & & & & & & $\begin{array}{c}97.435^{*} \\
(52.511)\end{array}$ \\
\hline $\begin{array}{l}\text { Idiosyncratic } \\
\text { skewness }\end{array}$ & & $\begin{array}{c}13.064^{* * *} \\
(1.350)\end{array}$ & & & $\begin{array}{c}10.133^{* * *} \\
(1.227)\end{array}$ & \\
\hline Issuing size & & & $\begin{array}{c}-17.189^{* * *} \\
(1.839)\end{array}$ & $\begin{array}{c}-18.341^{* * *} \\
(1.813)\end{array}$ & $\begin{array}{c}-17.665^{* * *} \\
(1.789)\end{array}$ & $\begin{array}{c}-17.220^{* * *} \\
(1.850)\end{array}$ \\
\hline $\begin{array}{l}\text { Issuing } P / E \\
\text { ratio }\end{array}$ & & & $\begin{array}{l}-0.124 \\
(0.079) \\
\end{array}$ & $\begin{array}{c}-0.176^{* *} \\
(0.081)\end{array}$ & $\begin{array}{l}-0.025 \\
(0.077) \\
\end{array}$ & $\begin{array}{l}-0.113 \\
(0.080) \\
\end{array}$ \\
\hline $\begin{array}{l}\text { Issuing } \\
\text { price }\end{array}$ & & & $\begin{array}{c}-0.363^{* * *} \\
(0.105)\end{array}$ & $\begin{array}{c}-0.338^{* * *} \\
(0.102)\end{array}$ & $\begin{array}{c}-0.289^{* * *} \\
(0.103)\end{array}$ & $\begin{array}{c}-0.366^{* * *} \\
(0.106)\end{array}$ \\
\hline $\begin{array}{l}\text { Market } \\
\text { return }\end{array}$ & & & $\begin{array}{c}1.622^{* * *} \\
(0.267)\end{array}$ & $\begin{array}{c}1.740^{* * *} \\
(0.259) \\
\end{array}$ & $\begin{array}{c}1.615^{* * *} \\
(0.258) \\
\end{array}$ & $\begin{array}{c}1.645^{* * *} \\
(0.272)\end{array}$ \\
\hline $\begin{array}{l}\text { Market } \\
\text { valuation }\end{array}$ & & & $\begin{array}{c}2.493^{* * *} \\
(0.267) \\
\end{array}$ & $\begin{array}{c}0.031 \\
(0.400) \\
\end{array}$ & $\begin{array}{c}2.381^{* * *} \\
(0.227) \\
\end{array}$ & $\begin{array}{c}2.523^{* * *} \\
(0.238) \\
\end{array}$ \\
\hline Firm age & & & $\begin{array}{c}0.166 \\
(0.311) \\
\end{array}$ & $\begin{array}{c}0.095 \\
(0.302) \\
\end{array}$ & $\begin{array}{c}0.153 \\
(0.302) \\
\end{array}$ & $\begin{array}{c}0.166 \\
(0.312) \\
\end{array}$ \\
\hline $\begin{array}{l}\text { Underwriter } \\
\text { reputation }\end{array}$ & & & $\begin{array}{c}0.530 \\
(2.742)\end{array}$ & $\begin{array}{c}2.146 \\
(2.681)\end{array}$ & $\begin{array}{c}0.516 \\
(2.665)\end{array}$ & $\begin{array}{c}0.441 \\
(2.751)\end{array}$ \\
\hline IPO year & No & No & No & Yes & No & No \\
\hline $\begin{array}{l}\text { No.of } \\
\text { observations }\end{array}$ & 879 & 879 & 879 & 879 & 879 & 879 \\
\hline$R^{2}$ & 0.037 & 0.089 & 0.271 & 0.318 & 0.320 & 0.267 \\
\hline Adjusted $R^{2}$ & 0.036 & 0.089 & 0.264 & 0.310 & 0.311 & 0.260 \\
\hline
\end{tabular}

Note: standard errors are between parentheses. ${ }^{*}: p<0.1 ;{ }^{* *}: p<0.05 ;{ }^{* * *}: p<0.01$. 


\subsubsection{Effect of skewness on stock's long term performance}

Table 5 reports the effect of skewness on stock's long term performance. Columns 1, 2, and 3 show the IPO stock's long term return for 120, 180 and 240 trading days. The results show that a standard deviation increase in expected skewness will reduce the 120 days long term return by $2.96 \%$ ( $4.23 \%$ for 180 days return and $3.75 \% 240$ days return). It indicates that investors' preference for lottery-like stocks will drive the stock's initial return up, while in the long run, the stock's price will convert to its true value and exhibit a long term reversal. Sufficient literature proves that long term underperformance of newly listed stocks are not good (Ritter, 1991; Loughran \& Ritter, 1995). Zheng (2014) claimed that the premiums for literary-like stocks in Chinese A-Share market are negative in long run, with annual return underperformed other stocks for at least 5\%. Our paper also indicates that initial public offerings, as a special category of lotterylike stocks, also follow this rule. That provides evidence for the second hypothesis.

\subsubsection{Effect of skewness on stock's turnover rate}

Table 6 reports the effect of skewness on stock's turnover rate. We use three types of dependent variables to capture new share's turnover rate: turnover rate group, institutional holdings increase and No. of institutional investors increase. Turnover rate group is an indicator variable which equals 1 if the stock is in the high or medium turnover rate group, and 0 if the stock is in the low turnover rate group. Columns 1 and 4 show that the coefficient of expected skewness is positive and significant, indicating that an standard deviation increase in expected skewness will increase the possibility for the new share to allocate to the high and medium turnover rate group by $2.319 \%$. Institutional holdings increase is an indicator variable equals 1 if holdings of the biggest ten institutional investors in the latest disclosure increase or remain the same compared to that reported before the day of IPO, 0 otherwise. No. of institutional investors increase is an indicator variable if the number of institutional investors in the latest disclosure increase or remain the same compared to that reported before the day of IPO, 0 otherwise. Columns $2 \& 5$, and Columns $3 \& 6$ show that increase in expected skewness will result in lower possibility of long-term institutional investor holding, indicating that new shares with high skewness are mainly held by individual investors in the long run. This aligns with the argument by Field \& Lowry (2009) that newly listed stocks are 
TABLE 5.

Impact of Gaming Preference on Long-Run Return Rate

\begin{tabular}{|l|c|c|c|}
\hline \multirow{2}{*}{} & \multicolumn{3}{|c|}{ Long-term return rate } \\
\cline { 2 - 4 } & 120 days & 180 days & 240 days \\
\cline { 2 - 4 } Expected & $(1)$ & $(2)$ & $(3)$ \\
\hline skewness & $-22.613^{* *}$ & $-32.317^{* * *}$ & $-28.603^{* * *}$ \\
Issuing size & $(5.701)$ & $(6.867)$ & $(7.138)$ \\
\hline Issuing $P / E$ ratio & $-3.008^{* * *}$ & $-2.426^{*}$ & $-2.350^{*}$ \\
& $(1.040)$ & $(1.252)$ & $(1.302)$ \\
\hline Issuing price & -0.049 & -0.057 & 0.049 \\
& $(0.046)$ & $(0.056)$ & $(0.058)$ \\
\hline Market return & $0.217^{* * *}$ & $0.215^{* * *}$ & $0.207^{* * *}$ \\
& $(0.059)$ & $(0.071)$ & $(0.073)$ \\
\hline Market & $-0.365^{* *}$ & $-0.424^{* *}$ & $-0.579^{* * *}$ \\
valuation & $(0.149)$ & $(0.179)$ & $(0.186)$ \\
\hline Firm age & 1.358 & $1.581^{* * *}$ & $1.960^{* * *}$ \\
& $(0.230)$ & $(0.277)$ & $(0.288)$ \\
\hline Underwriter & -0.067 & 0.030 & 0.056 \\
reputation & $(0.173)$ & $(0.209)$ & $(0.217)$ \\
\hline No. of observations & -0.198 & -0.541 & 0.041 \\
\hline$R^{2}$ & $(1.538)$ & $(1.852)$ & $(1.926)$ \\
\hline Adjusted $R^{2}$ & 879 & 879 & 879 \\
\hline Note: in the regre & 0.095 & 0.106 & 0.152 \\
\hline & 0.083 & 0.094 & 0.142 \\
\hline
\end{tabular}

Note: in the regression, we control the year of issuing which has no impact on the significance but increases $R^{2}$. Standard errors are between parentheses. ${ }^{*}: p<0.1$; $^{* *}: p<0.05$; $^{* *}: p<0.01$.

mostly traded by retailed investors, whose irrational trading activities lead to long-term underperformance of these stocks.

Table 7 reports the joint effect of investor sentiment and skewness preference on IPO first day return and long term performance. After controlling for investment sentiment, expected skewness still has a positive and a significant impact on first day return, but negative and significant impact on long term return. It indicates that skewness preference is not merely a measure capturing bullishness of investors, rather, it captures investors' gambling propensity. The interaction term of expected skewness and investor sentiment is significantly positive (negative) in Column 1 (Column 2 to 4$)^{15}$, showing that skewness preference has larger impact on first day return (long

\footnotetext{
${ }^{15}$ Note that we use the lot of chance to represent market mood, whose correlation is negative. Thus negative coefficient of interaction implies the complement of them.
} 
TABLE 6.

Estimations of Probit Model

\begin{tabular}{|l|l|l|l|l|l|l|}
\hline & \multicolumn{3}{|c|}{ Coefficient } & \multicolumn{3}{c|}{ Margin Probability } \\
\hline & $\begin{array}{l}\text { High or } \\
\text { medium } \\
\text { turnover } \\
\end{array}$ & $\begin{array}{l}\text { Institutional } \\
\text { holdings } \\
\text { rate group }\end{array}$ & $\begin{array}{l}\text { No. of } \\
\text { institutional } \\
\text { investors } \\
\text { increase }\end{array}$ & $\begin{array}{l}\text { High or } \\
\text { medium } \\
\text { turnover } \\
\text { rate group }\end{array}$ & $\begin{array}{l}\text { Institutional } \\
\text { holdings } \\
\text { increase }\end{array}$ & $\begin{array}{l}\text { No. of } \\
\text { institutional } \\
\text { investors } \\
\text { increase }\end{array}$ \\
\cline { 2 - 7 } & $(1)$ & $(4)$ & $(3)$ & $(4)$ & $(5)$ & $(6)$ \\
\hline Expected & $1.262^{*}$ & $-0.926^{* * *}$ & $-1.165^{* * *}$ & $0.177^{*}$ & $-0.342^{* * *}$ & $-0.331^{* * *}$ \\
Skewness & $(0.672)$ & $(0.342)$ & $(0.386)$ & $(0.094)$ & $(0.124)$ & $(0.108)$ \\
\hline Scale of & $-0.460^{* * *}$ & $0.103^{*}$ & $0.394^{* * *}$ & $-0.065^{* * *}$ & $0.038^{*}$ & $0.112^{* * *}$ \\
Financing & $(0.120)$ & $(0.062)$ & $(0.081)$ & $(0.017)$ & $(0.022)$ & $(0.023)$ \\
\hline Issued $P / E$ & 0.000 & 0.002 & $0.006^{*}$ & 0.000 & 0.001 & $0.002^{*}$ \\
Ratio & $(0.000)$ & $(0.003)$ & $(0.003)$ & $(0.000)$ & $(0.003)$ & $(0.001)$ \\
\hline Offering & -0.004 & $0.010^{* * *}$ & $-0.001^{*}$ & -0.001 & $0.004^{* * *}$ & -0.000 \\
Price & $(0.006)$ & $(0.004)$ & $(0.004)$ & $(0.001)$ & $(0.001)$ & $(0.001)$ \\
\hline Market Return & $0.120^{* * *}$ & 0.008 & $0.024^{* *}$ & $0.017^{* * *}$ & 0.003 & $0.007^{* *}$ \\
Ratio & $(0.023)$ & $(0.009)$ & $(0.010)$ & $(0.003)$ & $(0.003)$ & $(0.003)$ \\
\hline Market & -0.024 & $0.019^{*}$ & $-0.017^{* *}$ & -0.003 & $0.007^{* *}$ & $-0.005^{* *}$ \\
Valuation & $(0.030)$ & $(0.091)$ & $(0.008)$ & $(0.004)$ & $(0.003)$ & $(0.002)$ \\
\hline Company & -0.022 & -0.001 & -0.007 & -0.003 & -0.000 & -0.002 \\
Age & $(0.017)$ & $(0.010)$ & 0.012 & $(0.002)$ & $(0.004)$ & $(0.003)$ \\
\hline Underwriter & 0.263 & $-0.162^{*}$ & -0.018 & 0.036 & $-0.060^{*}$ & -0.005 \\
Reputation & $(0.169)$ & $(0.091)$ & $(0.101)$ & $(0.022)$ & $(0.034)$ & $(0.029)$ \\
\hline Observation & 703 & 877 & 877 & 703 & 877 & 877 \\
\hline
\end{tabular}

Note: in the regression, we control the year of issuing which has no impact on the significance but increases $R^{2}$. Standard errors are between parentheses. ${ }^{*}: p<0.1 ;^{* *}: p<0.05 ;^{* * *}: p<0.01$.

term return) when investors are bullish. Barberis and Huang (2008) found that investors become less sensitive to portfolio diversification as a result of high sentiment, thus leading to higher impact of skewness preference on stock return. It may be also due to that bullish investors allocating higher subjective probability on huge returns, amplifying the effect of skewness preference on stock return.

\subsubsection{Robustness Check}

Firstly, we check whether skewness preferences calculated from different time periods have impacts on the results. Therefore, in table 1 , we calculate expected skewness at 4 weeks, 6 weeks and 8 weeks. Each expected skewness calculated all exhibit the pattern that first day return increases with skewness, echoed with the regression results. In addition, for the 
TABLE 7.

Gaming Preference, Investor Sentiment and Price Trend of IPO

\begin{tabular}{|l|c|c|c|c|}
\hline & First day & 120 days & 180 days & 240 days \\
\cline { 2 - 5 } & $(1)$ & $(2)$ & $(3)$ & $(4)$ \\
\hline Expected & $65.256^{* * *}$ & $-27.389^{* * *}$ & $-38.756^{* * *}$ & $-35.960^{* * *}$ \\
skewness & $(11.771)$ & $(6.574)$ & $(7.942)$ & $(8.281)$ \\
\hline 1/oversubsc & $-3.464^{* * *}$ & $1.589^{* * *}$ & $1.583^{* * *}$ & $0.948^{*}$ \\
ription & $(0.756)$ & $(0.436)$ & $(0.527)$ & $(0.549)$ \\
\hline Expected & $-25.237^{* * *}$ & $7.418^{* *}$ & $8.631^{* *}$ & $7.756^{*}$ \\
skewness*Lot & $(5.705)$ & $(3.236)$ & $(3.910)$ & $(4.077)$ \\
\hline Issuing size & $-14.338^{* * *}$ & $-4.579^{* * *}$ & $-3.940^{* * *}$ & $-3.150^{* *}$ \\
& $(1.939)$ & $(1.113)$ & $(1.345)$ & $(1.402)$ \\
\hline Issuing $P / E$ & $-0.180^{* *}$ & -0.023 & -0.033 & 0.061 \\
ratio & $(0.079)$ & $(0.047)$ & $(0.056)$ & $(0.059)$ \\
\hline Issuing & $-0.280^{* * *}$ & $0.175^{* * *}$ & $0.175^{* *}$ & $0.186^{* *}$ \\
price & $(0.106)$ & $(0.059)$ & $(0.072)$ & $(0.075)$ \\
\hline Market & $1.714^{* * *}$ & $-0.390^{* * *}$ & $-0.453^{* *}$ & $-0.604^{* * *}$ \\
return & $(0.264)$ & $(0.148)$ & $(0.179)$ & $(0.186)$ \\
\hline Market & $2.252^{* * *}$ & 1.333 & $1.560^{* * *}$ & $1.956^{* * *}$ \\
valuation & $(0.236)$ & $(0.228)$ & $(0.276)$ & $(0.287)$ \\
\hline Firm age & 0.198 & -0.096 & 0.004 & 0.045 \\
& $(0.310)$ & $(0.172)$ & $(0.210)$ & $(0.217)$ \\
\hline Underwriter & 0.352 & -0.045 & -0.374 & 0.173 \\
reputation & $(2.710)$ & $(1.528)$ & $(1.846)$ & $(1.925)$ \\
\hline No. of observations & 879 & 879 & 879 & 879 \\
\hline$R^{2}$ & 0.289 & 0.109 & 0.115 & 0.156 \\
\hline Adjusted $R^{2}$ & 0.281 & 0.096 & 0.102 & 0.143 \\
\hline & Note: standard & $0.964)$ & $0.05 \%$ \\
\hline
\end{tabular}

Note: standard errors are between parentheses. ${ }^{*}: p<0.1$; $^{* *}: p<0.05$; $^{* * *}$ : $p<0.01$.

all the high/medium/low skewness portfolio calculated with different time periods, same skewness portfolio exhibit similar average first day return, indicating that skewness calculated with different time periods is robust. Similarly, we use different time periods to calculate idiosyncratic skewness and the results are robust.

Secondly, we matched IPO firms with public firms, and further reveal the impact of skewness preference on new share's long term price. Every IPO firms is matched with public firms with similar size and $P / E$ ratio in 
the same industry ${ }^{16}$. The figures below show the comparison of IPOs and matched stocks by $\mathrm{P} / \mathrm{E}$ and market capitalization.

FIG. 3. Plots of IPOs and Match Stocks
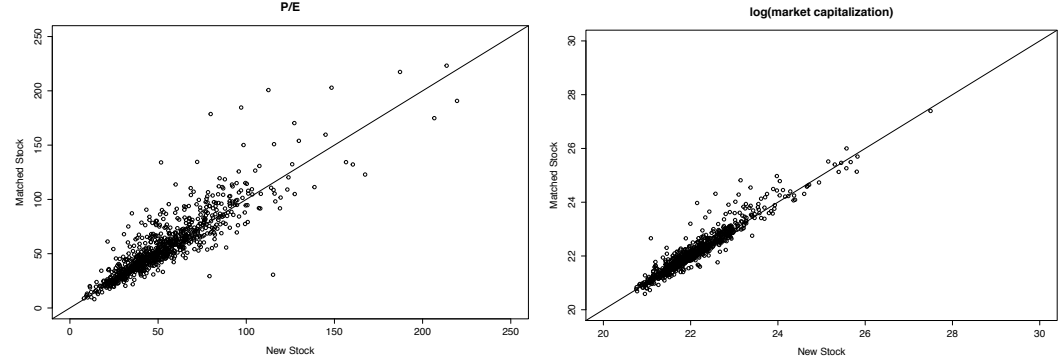

TABLE 8.

Gaming Preference and Long-Run Return Rate of IPO

\begin{tabular}{|c|c|c|c|c|}
\hline & \multicolumn{4}{|c|}{ Long-run Return(\%) } \\
\hline & & 120Days & 180Days & 240Days \\
\hline \multirow[t]{4}{*}{ Large Skewness } & IPO & -11.04 & -12.71 & -12.17 \\
\hline & Matched-group & -3.57 & -3.23 & -2.55 \\
\hline & \multirow[t]{2}{*}{ Difference } & 7.47 & 9.48 & 9.62 \\
\hline & & $(4.11)$ & $(4.36)$ & $(4.05)$ \\
\hline \multirow[t]{4}{*}{ Medium Skewness } & IPO & -7.35 & -5.28 & -5.70 \\
\hline & Matched-group & -0.83 & 0.33 & -1.72 \\
\hline & \multirow[t]{2}{*}{ Difference } & 6.52 & 5.61 & 3.98 \\
\hline & & $(3.34)$ & $(2.24)$ & $(1.57)$ \\
\hline \multirow[t]{6}{*}{ Small Skewness } & IPO & -3.88 & -1.47 & -5.26 \\
\hline & Matched-group & 2.89 & 3.22 & 0.64 \\
\hline & \multirow[t]{2}{*}{ Difference } & 6.77 & 4.69 & 5.91 \\
\hline & & $(3.40)$ & $(1.98)$ & $(2.37)$ \\
\hline & \multirow{2}{*}{$\begin{array}{l}\text { Difference between } \\
\text { groups with small } \\
\text { and high skewness }\end{array}$} & 0.70 & 4.79 & 3.71 \\
\hline & & $(0.32)$ & $(1.98)$ & $(1.34)$ \\
\hline
\end{tabular}

Note: t-values are between parentheses.

Table 8 shows that new share's long term performance is lower than matched public firm in low/medium/high skewness portfolios. In addition, the difference in long term performance between IPO firm and matched

\footnotetext{
${ }^{16}$ Suppose size is market capitalization, $p e$ is $P / E$ ratio, then we define $d_{i, j}=\left(\right.$ size $_{i}-$ size $\left._{j}\right)^{2}+\left(p e_{i}-p e_{j}\right)^{2}$ to measure the "distance" between IPO and other stocks in the same industry. We can find the closet company to IPO company after the first closing day. Note that industries are classified by SWS Index.
} 
public firm increases with the expected skewness, indicating that new share's long term performance decreases with skewness preferences.

Thirdly, behavioral finance highlights the impact of investor sentiment on stock return. We add alternative variables to control for investor sentiment, such as number of new accounts every month, and still find significant impact of skewness preference on first day return and long term return ${ }^{17}$.

\section{CONCLUSION}

This paper investigates the explaining power of investors' gambling attitude towards three main IPO anomalies in China: high first day return, high turnover rate and long term underperformance. In a stock market mostly composed by individual investors, we find that skewness preference is an important determinant of IPO anomalies.

Our theoretical work assumes that individual investors who can modify their subjective probability and prefer lottery-like assets, adopt Cumulative Prospect Theory preference, while rational institutional investors follow traditional expected utility theory. The interaction between individual investors with gambling preference and institutional investors in IPO market results in IPO anomalies. Specifically, the higher the skewness preference of individual investors, the higher the first day return, the higher the turnover rate, and the lower the long term performance.

Our empirical results confirm the predictions. Using a sample of $897 \mathrm{~A}$ share firms over 2009 to 2012, we find the following results: (1) Expected skewness is positively associated with new share's first day return. A standard deviation increase in expected skewness results in $5.478 \%$ first day return increase. (2) In the long run, high initial return stock will convert to its fundamental value. High expected skewness stocks reveal long term underperformance. (3) New shares with high skewness exhibit high turnover rate, as a result of institutional investors selling the shares and individual investors obtaining. (4) Investor sentiment amplifies the effect of skewness preference on stock return.

\footnotetext{
${ }^{17}$ Due to space limitations, detailed results are not reported, please contact Liheng $\mathrm{Xu}$ (ryanl 12210680129@fudan.edu.cn) if you are interested.
} 


\section{APPENDIX}

TABLE 1.

Distribution of Expected Skewness in Industries

\begin{tabular}{|l|c|c|c|c|c|c|c|}
\hline Industry & NO. & High & Median & Low & $\begin{array}{c}\text { Main- } \\
\text { Board }\end{array}$ & $\begin{array}{c}\text { SME- } \\
\text { Board }\end{array}$ & $\begin{array}{c}\text { Second- } \\
\text { Board }\end{array}$ \\
\hline Mechanical equipment & 205 & 25.85 & 39.51 & 34.63 & 22.68 & 22.72 & 33.73 \\
\hline Transportation equipment & 43 & 39.53 & 25.58 & 34.88 & 10.31 & 5.85 & 3.14 \\
\hline Chemicals & 90 & 23.33 & 40.00 & 36.67 & 9.28 & 10.54 & 14.12 \\
\hline Financial services & 11 & 18.18 & 36.36 & 45.45 & 9.28 & 0.47 & 0.00 \\
\hline $\begin{array}{l}\text { Construction and } \\
\text { construction equipment }\end{array}$ & 48 & 47.92 & 22.92 & 29.17 & 8.25 & 7.03 & 3.92 \\
\hline Transportation services & 14 & 42.86 & 42.86 & 14.29 & 6.19 & 1.17 & 1.18 \\
\hline Information services & 97 & 30.93 & 35.05 & 34.02 & 6.19 & 6.09 & 25.49 \\
\hline Nonferrous metals & 20 & 60.00 & 25.00 & 15.00 & 5.15 & 2.81 & 1.18 \\
\hline Textiles & 28 & 32.14 & 14.29 & 53.57 & 5.15 & 5.15 & 0.39 \\
\hline Commerce and trade & 14 & 28.57 & 42.86 & 28.57 & 4.12 & 1.87 & 0.78 \\
\hline Public utilities & 20 & 75.00 & 20.00 & 5.00 & 3.09 & 1.17 & 4.71 \\
\hline $\begin{array}{l}\text { Light industrial } \\
\text { manufacturing }\end{array}$ & 32 & 40.63 & 28.13 & 31.25 & 3.09 & 5.62 & 1.96 \\
\hline Mining & & & & & & & \\
\hline Leisure services & 3 & 66.67 & 0.00 & 33.33 & 2.06 & 0.23 & 0.00 \\
\hline Biomedicine & 4 & 50.00 & 50.00 & 0.00 & 1.03 & 0.47 & 0.39 \\
\hline $\begin{array}{l}\text { Agriculture, forestry, } \\
\text { animal husbandry } \\
\text { and fisheries }\end{array}$ & 24 & 29.58 & 46.48 & 23.94 & 1.03 & 6.56 & 16.47 \\
\hline Electrics & 24 & 45.45 & 13.64 & 40.91 & 0.00 & 4.68 & 0.78 \\
\hline Household appliances & 24 & 33.33 & 25.00 & 41.67 & 1.03 & 3.98 & 2.35 \\
\hline Information equipment & 39 & 33.33 & 28.21 & 38.46 & 0.00 & 3.04 & 10.20 \\
\hline Food and beverage & 22 & 0.00 & 50.00 & 50.00 & 0.00 & 0.23 & 0.39 \\
\hline Multi-product & 2 & 50.00 & 0.00 & 50.00 & 0.00 & 0.47 & 0.00 \\
\hline Real estate & 0.00 & 0.00 & 100.00 & 0.00 & 0.23 & 0.00 \\
\hline Steel & & & 29.17 & 1.03 & 3.28 & 3.53 \\
\hline Note: & 24.31 & 29.23 & 38.46 & 1.03 & 6.32 & 14.51 \\
\hline
\end{tabular}

Note: industry classifications are according "2011 Industry Standard" by Shenyin \& Wanguo Securities. 
TABLE 2

Summary Statistics of Variables

\begin{tabular}{lccccc}
\hline Variable & Num of Observations & Min & Standard Error & Min & Max \\
\hline First Day Return Rate (\%) & 879 & 36.036 & 45.198 & -26.333 & 626.744 \\
120 Days Return Rate (\%) & 879 & -3.983 & 22.499 & -49.513 & 107.599 \\
180 Days Return Rate (\%) & 879 & -1.748 & 27.268 & -54.933 & 142.254 \\
240 Days Return Rate (\%) & 879 & -1.547 & 29.113 & -63.506 & 164.125 \\
Turnover Rate (\%) & 879 & 70.157 & 20.252 & 12.107 & 95.920 \\
Lot of Chance (\%) & 879 & 1.459 & 3.063 & 0.098 & 65.521 \\
Market Return Rate (\%) & 879 & +0.908 & 4.979 & -15.341 & 16.474 \\
Skewness & 879 & 0.053 & 0.131 & -0.371 & 0.475 \\
Expected Skewness (4 Weeks) & 879 & 0.089 & 0.153 & -0.402 & 0.536 \\
Expected Skewness (9 Weeks) & 879 & 0.033 & 0.120 & -0.294 & 0.421 \\
Right Skewness & 879 & 0.148 & 0.028 & 0.072 & 0.351 \\
Left Skewness & 879 & 0.135 & 0.033 & 0.054 & 0.301 \\
Heterogeneity Skewness & 879 & 0.149 & 1.074 & -3.484 & 4.761 \\
Offering P/E & 879 & 49.426 & 20.637 & 7.170 & 150.820 \\
Financing Scale & 879 & 1.206 & 3.284 & 0.039 & 68.529 \\
Company Age & 879 & 10.734 & 4.283 & 0.805 & 29.074 \\
Offering Price & 879 & 26.072 & 14.901 & 2.580 & 148.000 \\
Overall P/E & 879 & 18.101 & 6.171 & 10.311 & 34.008 \\
Underwriters Reputation & 879 & 0.370 & 0.483 & 0 & 1 \\
Outperform & 877 & 0.612 & 0.488 & 0 & 1 \\
Shareholding & 877 & 0.774 & 0.418 & 0 & 1 \\
\hline
\end{tabular}

\section{REFERENCES}

Bali, Turan G., Nusret Cakici, and Robert F. Whitelaw, 2011. Maxing out: Stocks as Lotteries and the Cross-section of Expected Returns. Journal of Financial Economics 99(2), 427-446.

Barberis, Nicholas, and Ming Huang, 2007. Stock as Lotteries: The Implications of Probability Weighting for Security Prices. American Economic Review 98(5), 20662100 .

Battalio, R., and R. Mendenhall, 2005. Earnings Expectation, Investor Trade Size, and Anomalous Returns around Earnings Announcements. Journal of Financial Economics 77, 289-319.

Boyer, B., and K. Vorkink, 2014. Stock Option as Lotteries. Journal of Finance 69(4), 1485-1527.

Boyer, B., T. Mitton, and K. Vorkink, 2010. Expected Idiosyncratic Skewness. Review of Financial Studies 23(1), 169-202.

Brunnermeier, M., C. Gollier, and J. Paker, 2007. Optimal Beliefs, Asset Prices, and the Preference for Skewed Returns. American Economic Review 97(2), 159-165. 
Brunnermeier, Markus K., and Jonathan A. Parker, 2005. Optimal Expectation. American Economic Review 95(4), 1092-1118.

Chang, Y., P. Christoffersen, and K. Jacobs, 2013. Market Skewness Risk and the Cross Section of Stock Returns. Journal of Financial Economics 107(1), 46-68.

Chemmanur. T., G. Hu, and J. Huang, 2010. The Role of Institutional Investors in Initial Public Offerings. Review of Financial Studies 23, 4496-4540.

Conrad, J., N. Kapadia, and Y. Xing, 2014. Death and Jackpot: Why do Individual Investors Hold Overpriced Stocks. Journal of Financial Economics 113(3), 455-475.

Cook, D., R. Kieschnick, and R. Van Ness, 2006. On the Marketing of IPOs. Journal of Financial Economics 82(1), 35-61.

De Long, J., A. Shleifer, L. Summers, and R. Waldmann, 1990. Noise Trader Risk in Financial Markets. Journal of Political Economy 98(4), 703-738.

Derrien, F., 2005. IPO Pricing in "Hot" Market Condition: Who leaves money on the table. Journal of Finance 60(1), 487-521.

Eraker, B., and J. Ready, 2015. Do Investors Overpay for Stocks with Lottery-Like Payoffs? An Examination of the Returns on OTC Stocks. Journal of Financial Economics 155(3), 486-504.

Fama, E., and K. French, 1993. Common Risk Factors in the Returns on Stock and Bonds. Journal of Financial Economics 33(93), 3-56.

Field, L., and M. Lowry, 2009. Institutional versus Individual Investment in IPOs: The Importance of Firms Fundamentals. Journal of Financial and Quantitative Analysis 44(3), 489-516.

Green, C., and B. Hwang, 2012. Initial Public Offerings as Lotteries: Skewness Preference and First Day Returns. Management Science 58(2), 432-444.

Han, L., and Y. Wu, 2007. Investor sentiment and IPO anomalies. Management World 3, 51-61.

Harvey, C., and R. Siddique, 2000. Conditional Skewness in Asset Pricing Tests. Journal of Finance 55(2), 1263-1295.

Ibbotson, G., 1975. Price Performance of Common Stock New Issues. Journal of Financial Economics 2(3), 235-272.

Jiang, H., 2007. Price Behavior of a Share IPO Cased on Inefficient Market. Journal of Financial Research 8, 90-102.

Kahneman, D, and A. Tversky, 1979. Prospect Theory: An Analysis of Decision under Risk. Econometrica 68(3), 263-291.

Kahneman, D, and A. Tversky, 1992. Advances in Prospect Theory: Cumulative Representation of Uncertaity. Journal of Risk and Uncertainty 5(4), 297-323.

Kraus, A., and H. Litzenberger, 1976. Skewness Preference and the Valuation of Risk Assets. Journal of Finance 31(4), 1085-1100.

Kumar, A., 2005. Institutional Skewnwss Preferences and the Idiosyncratic Skewness Premium. Working Paper.

Kumar, A., 2009. Who Gambles in the Stock Market? Journal of Finance 64(4), 1889-1933.

Li, D., X. Li, H. Yu, and W. Zhu, 2014. IPO pricing and Bookbuilding. Economic Research 7, 151-164.

Ljungqvist, A., V. Nanda, and R. Singh, 2006. Hot Markets, Investor Sentiment, and IPO Pricing. Journal of Business 79(4), 1667-1702. 
Loughran, T., and J. Ritter, 2005. The New Issues Puzzle. Journal of Finance 50(1), 23-51.

Markowitz, H., 1952. Portfolio Selection. Journal of Finance 7(1), 77-91.

Merton, R., 1992. Continuous-Time Finance, Wiley-Blackwell Press.

Mitton, T., and K. Vorkink, 2007. Equilibrium Underdiversification and the Preference for Skewness. Review of Financial Studies 20(4), 1255-1288.

Shao, X., H. Wu, Z. Li, and D. Tang, 2011. Anomalies of High First Day Turnover Rate in China's IPO Market. Financial Studies 9, 122-137.

Ritter, J., 1984. The "Hot" Issue Market of 1980. Journal of Business 57(2), 215-240.

Ritter, J., 1991. The Long-run Performance of Initial Public Offerings. Journal of Finance 46(1), 3-27.

Ritter, J., and I. Welch, 2002. A Review of IPO Activity, Pricing and Allocations. Journal of Finance 57(4), 1795-1827.

Zhang, Y., 2006. Individual Skewness and the Cross-section of Average Stock Returns. Working Paper.

Zheng, Z., and Q. Sun, 2013. Stock as Lotteries: Evidence from Chinese Stock Market. Economic Research 5, 128-140. 